\title{
Rethinking the micro-foundations of macroeconomics: insights from behavioural economics
}

\author{
Michelle Baddeley \\ Bartlett School of Construction and Project Management, UCL, London, UK
}

In the aftermath of the financial crisis, macroeconomics is at a crossroads: on the one hand, the analytically rigorous, assumption-based approaches based on dynamic stochastic general equilibrium (DSGE) models lack intuitive plausibility and predictive power; on the other hand, alternative models lack an underlying analytical core. Behavioural economics offers a potential solution if it can unify intuition and analytical rigour. The aim of this paper is to assess the extent to which macroeconomics can embed behavioural and psychological insights from behavioural microeconomic analysis in order to build a rigorous and intuitively plausible understanding of how economic systems, including the macroeconomy and the financial system, work.

Keywords: macroeconomics, micro-foundations, behavioural economics, animal spirits

JEL codes: DO5, EOO

\section{INTRODUCTION}

Criticisms of mainstream dynamic stochastic general equilibrium (DSGE) models emerge from the fact that they are based on a number of unrealistic assumptions about rational, self-interested, atomistic behaviour. These assumptions do not match the behaviours we usually observe in the real world. In recent years, behavioural economics has offered some profound insights into the role that behavioural constraints play in undermining 'rational' behaviour by individuals, but bringing these insights into macroeconomic analysis is problematic for a number of reasons.

Behavioural economics focuses on individual differences and heterogeneity, and standard macroeconomic models generally rely on some form of representative agent hypothesis; this allows the macroeconomy to be seen as essentially an aggregation of microeconomic relationships. Standard economic approaches also tend to assume that people are atomistic, operating without regard to others. This also facilitates an additive approach. In contrast, behavioural/ experimental economics shows how individual behaviours are affected by a wide range of social influences such as conventions, herding, social learning, social norms and social preferences (for example, inequity aversion).

In theory, aggregating microeconomic relationships to construct a macro model means that a complex problem can be transformed into a simple additive problem. As recurrent financial crises have amply shown, however, this simplistic approach sidelines many of the complexities that generate instability in the first place. If the chances of future crises are to be reduced, a more realistic understanding of how macroeconomic systems work is needed.

Received 29 August 2013, accepted 15 December 2013 
Once the restrictive assumptions of standard economic analyses are relaxed it becomes difficult to see how the whole can be understood in terms of the sum of its parts. Behavioural economics has the potential to introduce a lot of complexity into macroeconomic models and these can be captured using new methodological tools, enabling a move away from the linear, additive worlds assumed by conventional macro-econometricians.

The first major goal of this paper is to develop a robust behavioural approach to the macroeconomy incorporating realistic assumptions grounded in insights from behavioural economics, psychology and sociology. This approach reconciles ideas from macroeconomics about the role played by animal spirits, confidence, conventions and expectations with insights from behavioural economics and economic psychology about cognitive bias, emotions and social influences. The main focus will be on understanding the connections between animal spirits, optimism/pessimism bias and present bias - using these insights to construct macroeconomic models with realism and external validity.

Four sets of behavioural and psychological factors affecting the macroeconomy will be explored in this paper:

- social factors, including conventions, herding, social learning and peer influences;

- cognitive bias;

- present bias and hyperbolic discounting; and

- psychological factors, including personality, confidence, optimism and animal spirits.

The connections with macroeconomic policy will also be explored, focusing in particular on the limits that behavioural constraints impose on macroeconomic policy flexibility in the real world, particularly in an age of austerity.

Section 2 of this paper will analyse some key ideas from behavioural economics with relevance for macroeconomic analysis; Section 3 will concentrate on animal spirits as the behavioural factor that is most commonly the focus of macroeconomic analyses; in Section 4, some hypotheses that could be used to create a behavioural macroeconomic model built on animal spirits will be outlined, and the building blocks for an original behavioural macroeconomic model will be presented. The paper will conclude with an outline of potential policy implications in Section 5 and directions for future research in the closing Section 6.

\section{BEHAVIOURAL INFLUENCES ON MACROECONOMIC BEHAVIOUR}

Attempts to capture behavioural and psychological factors within the macroeconomy were pioneered by Keynes $(1936 ; 1937)$ and Katona $(1975)$. Katona focused on impacts on consumption whereas Keynes had a wider focus and, according to Keynes himself, his General Theory of Employment, Interest and Money is an analysis of the psychological forces impacting on the macroeconomy. In Keynes's taxonomy, key psychological forces include the propensity to consume, and liquidity preference. Keynes also focuses on sociopsychological influences and phenomena including conventions, herding, social learning and beauty contests. These are all affected by organically driven macroeconomic forces such as the state of confidence and the state of long-term expectation.

\subsection{Conventions, herding and social influence}

Herding can be analysed as a response to uncertainty and imperfect information. For example, as observed by Keynes, people may follow the crowd if they think that other people are better informed. This makes the macroeconomy vulnerable to instability; herding 
externalities are generated when private information is ignored and when expectations are driven by crowd psychology they will have no solid anchor. This affects not only individual decision-making but also the general state of business confidence. It also generates selffulfilling prophecies and speculative episodes. Keynes argues that, during financial speculation for example, people will purchase a tulip bulb, house or (today) a dotcom share at a seemingly exorbitant price not because they independently believe that the object is worth the cost but because they believe that other people think that it is. In the modern, globalised, computerised and deregulated world, these impacts are amplified.

Standard economic analysis can capture a form of herding consistent with weaker rationality - via Bayesian models that do not assume rational expectations operating within efficient financial markets but nonetheless retain a view of rationality as the outcome of learning/probability updating based on a mathematical algorithm, viz. Bayes's rule (for example, see Scharfstein/Stein 1990; Banerjee 1992; Bikhchandani et al. 1992; 1998; Avery/Zemsky 1998; Chamley 2004). Behavioural economics offers broader insights by allowing that herding and social influence may also/instead be the product of broader social influences such as peer pressure (Baddeley 2010). Also social learning may be the outcome of non-quantitative reasoning, for example when people use shortcuts and follow simple rules of thumb, habits and routines. Imitation qualifies as a 'fast and frugal heuristic' in social situations (Gigerenzer/Goldstein 1996; Gigerenzer 2007).

Sociological forces play an important role in the macroeconomy: socially propelled conventions encourage speculators to believe what others believe and to do what others do (Keynes 1930; 1936; 1937). Emotional contagion can lead to speculative euphoria, which spreads during manic phases. This is a crucial catalyst in economic and financial booms but, as Minsky observed, the seeds of instability are sown in the boom phase and just as speculative bubbles precipitate excessive leveraging during boom times, when the crisis hits excessive pessimism and extreme risk aversion precipitate rapid busts and deleveraging (Minksy 1978; 1986; 1992; Davidson 1997; 2008).

\subsection{Cognitive bias}

Broader concepts of rationality have been developed from Herbert Simon's analyses of rationality. He made a useful distinction between substantive rationality, consistent with the conventional maximising approach assumed in standard economics, and procedural rationality in which people employ heuristics (that is, quick decision-making rules of thumb). Looser forms of decision-making associated with procedural rationality may generate cognitive bias and there are many forms of cognitive bias that affect decision-making (see Tversky/Kahneman 1974; Baddeley et al. 2005; Baddeley 2006). The cognitive biases and heuristics that have the biggest impact on macroeconomic instability include the availability heuristic (when decisions are based on accessible information such as recent news events evoking vivid, salient memories). Persistence is generated when people are slow to adjust to economic events - with implications for inflationary expectations, wage rigidity, unemployment hysteresis and unsustainable housing/asset price bubbles. These impacts are exacerbated by the anchoring/adjustment heuristic: expectations are anchored around subjectively determined reference points, leading to sustained speculative episodes and self-fulfilling prophecies. Behavioural economics also explains how these reference points are determined by social factors and social norms. Other heuristics and biases include overconfidence, loss aversion and myopia - all of which have been identified as anomalies in the behavioural finance literature. These and other forms of cognitive bias will mean that the macroeconomy cannot automatically correct in the face of shocks. Instead there will be sustained cycles of boom and bust alongside hysteresis and persistence in unemployment. 


\subsection{Present bias and hyperbolic discounting}

A form of cognitive bias that is of particular importance in the macroeconomy is present bias and it plays a key role because it distorts discount rates and discount factors. In mainstream analysis short-termism, impatience can be captured by high discount rates, but behavioural economics develops a richer understanding of preference reversals and time inconsistency by replacing the conventional assumption of exponential discounting with an assumption of 'hyperbolic' or 'quasi-hyperbolic' discounting (Thaler/Shefrin 1981; Laibson 1997; Angeletos et al. 2001; Frederick et al. 2002): a person may have good intentions about saving for the future but, in the present, will be unable to resist tempting alternatives for splurging money. Time inconsistency will also generate problems of temptation and procrastination (O'Donoghue/Rabin 1999): people are often tempted by financial choices that may be 'too good to be true', exacerbating over-optimism.

A large volume of experimental evidence shows that individuals' discount functions are not stable and that people tend to exhibit disproportionate impatience in the short-run. Models embedding standard exponential discounting predict that if a person is making choices over a given time interval then those choices should be stable over time: if I prefer to have chocolate cake today rather than wait until tomorrow, then, if I have a stable rate of time preference, I should also prefer to have my chocolate cake in a year rather than wait a year and a day. A large volume of experimental evidence, from psychology, neuroscience and ecology as well as behavioural economics, does not confirm this prediction: people prefer to take rewards sooner when choosing for the short-term, but are prepared to wait for longer when choosing for the long-term: they want their chocolate cake today but will be prepared to wait for a year and a day if their choice is pushed forward in time. This is not consistent with the standard exponential discounting assumption.

Insights about hyperbolic and quasi-hyperbolic discounting have been applied to macroeconomic analysis. For example, Laibson (1997) shows that standard discount functions do not capture the fact that people hold onto illiquid assets and liquid assets simultaneously because the illiquid assets are their 'golden eggs' and will only realise their value if a person holds onto them for long periods of time, regardless of their short-term financial position. Similarly, Angeletos et al. (2001) show that quasi-hyperbolic discount functions can explain the fact that households will simultaneously hold credit card debts at high interest rates alongside significant stocks of illiquid wealth earning low rates of return. A rational expectations model would predict that they should sell the illiquid wealth (or borrow against those assets) in order to pay off their credit card bills. Angeletos et al.'s empirical evidence shows that behavioural discount functions that allow preference reversals and present bias better capture real-world financial decisionmaking.

\subsection{Personality and emotions}

Personality, emotion and decision-making are intertwined in the economic world but, until recently, economic analysis has neglected the role of personality and emotion in economic decision-making (Elster 1996; 1998). People's preferences, for example their time and risk preferences, are affected by their personalities, and personality generates predispositions to feel certain emotions. Risk for example can be characterised as a feeling and some personality types are more vulnerable to risk aversion or risk seeking than others. Greed, hope and fear are likely to be the emotions most relevant to macroeconomic and financial instability because feedback effects intensify fear responses to risk and may precipitate panics. Other emotions will affect financial markets, for example the irrational 
exuberance seen in bullish markets reflects an interaction of hope and greed (Shiller 2000; 2003). When individual panics precipitate 'social panics' this may reflect interplay between risk, anxiety and fear (Loewenstein et al. 2007).

Standard economic analysis tends to associate emotions with irrationality, but psychology and neuroscience have shown that emotions have an important role to play. For example, Antonio Damasio's (2005) 'somatic marker hypothesis' focuses on the positive role played by emotions in providing important physiological cues to guide decision-making (explored in more depth below). Elster (1996) and Loewenstein (1996) emphasise that emotions and visceral factors are neither rational nor irrational because they cannot be chosen and emotions do not necessarily interfere with rationality. Emotions may be important 'tie-breakers' when outcomes are indeterminate in rational choice models. The influence of visceral factors varies in intensity - exerting overwhelming influences when people are in a 'hot state', whilst cognitive factors will exert more influence in 'cold' psychological states (Bernheim/Rangel 2004).

Behavioural economics and neuroeconomics emphasise the important insight that rationality is not a binary variable; it is not about being rational or irrational. Instead, economic and financial behaviour is the outcome of interactions of different decisionmaking systems. Again, this insight is foreshadowed by Keynes (1936), as is explained below.

Keynes (1936; 1937), Minsky $(1978 ; 1986)$ and Mini $(1990)$ argue that moods and emotions will have an impact on the macroeconomy. If confidence is strong and people are optimistic, then the macroeconomy will be vulnerable to waves of euphoria, optimism, and overconfidence precipitating herding and speculative bubbles; but when the state of confidence is weak and people are pessimistic, then the macro-economy will be prone to slumps and financial crises. Akerlof/Shiller (2009) develop these insights in explaining that these forces will spread via storytelling, word of mouth and false intuitions, generating financial contagion. Asset prices will be susceptible to feedback loops. Leverage will magnify instability with knock-on effects for the real economy as herding and speculative bubbles exacerbate real instability, particularly via their impacts on fixed asset investment.

\section{ANIMAL SPIRITS AND THE MACROECONOMY}

This section will explain that animal spirits capture some of the aspects of the sociopsychological influences outlined in Section 2. A key problem with animal spirits is conceptualising and operationalising them in a practically meaningful way. The role played by emotions in the macro-economy is gaining prominence and most attempts at constructing a behavioural macroeconomic model have embedded animal spirits in one form or another.

J. Maynard Keynes (1936: 161-162) most famously analysed animal spirits in the context of the macroeconomy:

... a large proportion of our positive activities depend on spontaneous optimism. ... Most, probably, of our decisions to do something positive ... can only be taken as a result of animal spirits of a spontaneous urge to action rather than inaction ... Only a little more than an expedition to the South Pole, is [enterprise] based on an exact calculation of benefits to come ... [I]f the animal spirits are dimmed and the spontaneous optimism falters ... enterprise will fade and die ... Individual initiative will only be adequate when reasonable calculation is supplemented and supported by animal spirits. 
Animal spirits are also: cyclical; not easily measurable; sensitive to social and political changes; affected by uncertainty, the state of confidence and social mood; and they interact with financial constraints and the state of credit.

Interpreting Keynes's animal spirits in the light of insights from behavioural economics, they capture an interaction of a willingness to act (for example, when entrepreneurs invest in expanding their business), spontaneity, and a mood of optimism (possibly magnified by optimism bias). All of these factors can be connected with risk and time preferences.

Specifically, animal spirits may connect with behavioural discounting functions if they are associated with more forward-looking behaviour. Entrepreneurs' animal spirits and optimism reflect a type of future bias: entrepreneurs imagine a future more rosy than objective mathematical evidence suggests. They invest in fixed assets in the hope that these will deliver profits in the future and may be doing this because they value future outcomes more highly - and, unlike the standard models which assume stable time preference, future bias can be captured by discount functions that allow a shifting rate of time preference. Similarly, spontaneity and a willingness to act may connect with risk-seeking preferences.

Modern empirical analyses of animal spirits often sideline these psychological/ emotional factors. The most common empirical strategy is to embed animal spirits as an exogenous variable, for example as random noise (see, for instance, Woodford 1988; 1990; Howitt/McAfee 1992; Farmer/Guo 1994; De Grauwe 2011; 2012a; 2012b). In these approaches, animal spirits are often made synonymous with business/consumer confidence, but empirically separating exogenous animal spirits from other exogenous shocks is problematic. Akerlof/Shiller (2009) take a different approach in (arguably) developing Keynes's insights. They generalise Keynes's concept, describing animal spirits as synonymous with all psychological factors affecting a range of economic behaviours. They develop a taxonomy of 'animal spirits', focusing on five: confidence, fairness, corruption, money illusion and story-telling - all of which can magnify macroeconomic and financial instability.

This listing is ad hoc and is equivocally true to Keynes's original intentions. Akerlof/ Shiller's animal spirits are a 'catch-all' category to cover most psychological influences and therefore the term 'animal spirits' is not particularly meaningful in this sense. Keynes analysed animal spirits just in the context of entrepreneurship: uncertainty about the future prevents entrepreneurs from properly calculating the future benefits of their business decisions and so animal spirits take over, precipitating 'a spontaneous urge to action'. Keynes links his conception with the original analysis of animal spirits by Galen - a Greek physician who analysed animal spirits in the context of Hippocrates' four humours.

Galen of Pergamum (AD 129- c. 200) was Chief Physician at the Pergamum gladiator school. ${ }^{1}$ He pioneered medical experimentation and animal dissection and he popularised the animal spirits theory of the nervous system, linking the digestion that generates animal spirits with Hippocrates' description of the four humours (blood, phlegm, yellow bile, black bile) which in turn connect with emotional states. Animal spirits flow into the blood ('sanguine' implies 'optimistic'). They are weightless, invisible spirits flowing through hollow nerves to trigger action, sensation and cognition. So the original conception of animal spirits emphasises action and connects cognitive with emotional decision-making (Costandi 2006).

1. Koppl $(1991 ; 2002)$ analyses the influence of these animal spirits and argues that Keynes owes more to Descartes than Galen in describing animal spirits as drivers of action in circumstances where there is no good objective, mathematical basis for action. 
In the absence of a basis for rational calculation, entrepreneurs' decisions will be propelled by animal spirits and entrepreneurs will continue to act, even when they have no objective mathematical expectation to justify their actions. Emotions play a key role in this and animal spirits do have an emotional component - though it is a matter of contention to what extent animal spirits are fundamentally about emotions. Interesting insights from neuroscience can help to resolve the puzzle. Keynes foreshadows the dual systems approaches common to some modern neuroeconomic analyses when he describes interactive decision-making:

... human decisions affecting the future ... cannot depend on strict mathematical expectation ... It is our innate urge to activity which makes the wheels go round, our rational selves choosing between the alternatives as best we are able, calculating where we can, but often falling back for our motive on whim or sentiment or chance. (Keynes 1936: 163)

Animal spirits also potentially connect with important insights about the constructive role that emotions play in decision-making, for example as explored by Antonio Damasio (2005) in his Somatic Marker Hypothesis (SMH). Emotions interact with cognition to guide action. ${ }^{2}$ Somatic markers are the associations between stimuli and emotional states and they guide the reasoning process by providing a somatic, bodily signal or feeling about what is the best course of action. The essential role played by emotion is illustrated in cases when affect and cognition are disconnected. A wide range of neuroscientific lesion patient studies (studies of patients suffering localised brain damage) illustrate that impaired affective responses will inhibit normal functioning. Early evidence comes from a case study of Phineas Gage:

The equilibrium or balance, so to speak, between his intellectual faculties and animal propensities, seems to have been destroyed. He is fitful, irreverent, indulging at times in the grossest profanity ... impatient of restraint or advice when it conflicts with his desires, at times pertinaciously obstinate, yet capricious and vacillating, devising many plans of future operations, which are no sooner arranged than they are abandoned in turn for others appearing more feasible ... (Harlow 1868: 339-340)

Similar behaviours have also been observed in a large number of modern lesion patient studies (see, for example, Bechara/Damasio 2004; Damasio 2005).

Economists are starting to develop connections between emotions, animal spirits and the SMH. Martins (2011) analyses the SMH generally in economics; Dow/Dow (1985; 2011), Loewenstein/O’Donoghue (2004), Dow (2011) and Koutsobinas (2011) analyse connections between animal spirits and emotions in the macroeconomy. These approaches could be unified to develop an approach focusing on the SMH as an operational model of how emotions underlie the positive urges to action associated with animal spirits.

\section{MODELLING ANIMAL SPIRITS}

As explained above, a complex nexus of factors affects the macroeconomy, including social influences such as herding and conventions; heuristics and biases; shifting risk preferences; time inconsistency; and moods, emotions and animal spirits. Understanding how these interact does require the problem of heterogeneity to be addressed, because whilst

2. See also Elster $(1996 ; 1998)$ on emotions in economics. 
conventional macroeconomics is founded on an assumption of homogeneity - enabling simple aggregation - significant individual differences in terms of personality, preferences and demographics will limit the justifiability of the homogeneity assumption.

The complex interaction of influences means that modelling animal spirits in the macroeconomy using standard econometric approaches is problematic, compounded by the fact that animal spirits are not easily quantifiable. Following Dow/Dow (1985; 2011) and Dow (2011), as well as Galen's and Keynes's fundamental insights, this section will focus on emotions that seem to connect most closely with behavioural macroeconomics and its emphasis on animal spirits. The role played by optimism and pessimism is crucial because these emotions connect with the animal spirits that propel decisions to act now rather than later. This can be connected with time preference and discount functions.

As noted above, in modern interpretations animal spirits are seen as being synonymous with business/consumer confidence and are incorporated as an add-on to standard macro models. Key models include those presented by Woodford (1988) and Howitt/McAfee (1992); in these approaches, animal spirits are modelled as exogenous random noise in animal spirit cycles, giving a two-state Markov process with switching between high and low demand states. ${ }^{3}$ The problem with these approaches is that they do not substantively embed the essence of animal spirits and psychological factors more generally. Bringing behavioural economics more clearly into the analysis will require a focus on interactions of mood/emotion, time/risk preferences and cognitive bias. Social and political contexts will also be important because they affect the impacts of behavioural forces. An alternative approach is to develop a model in which buoyant animal spirits drive discount factors and generate pro-cyclical future bias and optimism, with anaemic animal spirits driving counter-cyclical present bias and pessimism. Fluctuating animal spirits will be associated with fluctuations in discount factors, and together they will drive business confidence and entrepreneurial activity.

\subsection{Key hypotheses}

What would a powerful behavioural macroeconomics model look like? Some key hypotheses that can be used as a basis for a meaningful animal spirits model include:

Hypothesis 1: Macroeconomic actors are not substantively rational; that is, their decisions are not the outcome of an objective, mathematical process. They use heuristics and are prone to make systematic mistakes, especially when their decisions are distorted by social influences and herding. Some cognitive biases may have positive impacts. For example: optimism bias may boost animal spirits and entrepreneurship, ensuring higher levels of investment and production than there might have been otherwise. Social influences such as herding may enable learning if other people's actions are genuinely informative.

Hypothesis 2: The propensity to make systematic mistakes correlates with individual differences including demographic factors, socio-economic characteristics and personality traits.

Hypothesis 3: Propensities for risk-seeking versus risk aversion correlate with predispositions towards optimism versus pessimism and these in turn connect with animal spirits - defined here as Keynes originally envisaged: a propensity to act now rather than later.

3. See also Farmer/Guo (1994) and De Grauwe (2011; 2012a). 
Hypothesis 4: Optimism/pessimism and risk-aversion/risk-seeking affect individuals' discount functions. Different macroeconomic actors operating in different contexts will discount the future in different ways. As a working hypothesis: optimism connects with animal spirits and is associated with more forward-looking behaviour such as decisions of entrepreneurs to act today to invest in fixed assets delivering future rewards; this insight should be complemented by an empirical methodology set up to ensure that the hypotheses are refutable/falsifiable.

Hypothesis 5: Discount rates are determined endogenously by economic expectations and psychological factors. They will vary across individuals. ${ }^{4}$

\subsection{A behavioural micro-founded macroeconomic model}

The hypotheses above can be used to construct a behavioural micro-founded macroeconomic model using a two-stage modelling approach - with behavioural factors, including animal spirits, included as explanatory variables.

In standard macroeconomic models - including DSGE models - the discount rate is assumed to be exogenous and stable and the discount factor evolves in a deterministic way. In behavioural models, whilst the discount rate is not a constant, it is nonetheless a deterministic function of time and so evolves in a stable, deterministic way. In the animal spirits model presented here, the discount factor is similar to that seen in hyperbolic discounting models but with an endogenous discount factor driven by animal spirits and other socio-psychological factors.

The approach can be illustrated for consumption and investment. Assuming that a household spends and invests subject to an income constraint, then $Y=w L+r K$, where $w$ is the wage, $L$ is labour, and $r$ is the return on capital $K$. Simplifying to allow that future investment is just postponed consumption: consumption, $c_{t}$, provides utility today; investment, $i_{t}$, generates consumption and therefore utility in the future. A standard approach assumes that consumers maximise the discounted value of expected utility, $u_{\mathrm{t}}$, over an infinite time horizon:

$$
\begin{aligned}
& \max \sum_{t=0}^{\infty} \beta^{t} u\left(c_{t}\right) \quad 0<\beta<1 \\
& \text { s.t } c_{t}+i_{t} \leq w_{t} l_{t}+r_{t} k_{t}
\end{aligned}
$$

Behavioural influences can be incorporated into this model as a determinant of $\beta$, the discount factor. There are three approaches to identifying $\beta$, as follows:

Standard neoclassical discount factor

$$
\beta=\frac{1}{1+\rho}
$$

where $\rho$ is the discount rate.

4. These insights are consistent with Irving Fisher's (1930) analysis of the rate of interest. Even though Fisher is often identified as the grandfather of orthodox analyses of inter-temporal decisionmaking (for example, see Mankiw's Macroeconomics (2012) for his analysis of Fisher's two-period consumption model), some of Fisher's profound insights about what affects time preference have been lost in modern macroeconomic analysis. 


\section{Behavioural approach I: deterministic hyperbolic discount function ${ }^{5}$}

$$
\beta=\frac{1}{1+t}
$$

where $t$ is the time period from today until when the consumption occurs - that is, the delay between now and the consumption period.

\section{Behavioural approach II: endogenous hyperbolic discount function}

$$
\beta=f(t, X, Z)
$$

where $X$ is a vector of behavioural/psychological variables including animal spirits, mood, perceptions of risk and business confidence; and $Z$ is a vector of social/contextual influences, for example measures of economic performance (employment, unemployment, production), financial market conditions, socio-political environment, etc.

This style of analysis can be extended to model other macroeconomic and financial phenomena. Empirically, it is possible it could be modelled using standard econometric techniques if good proxies for socio-psychological factors can be identified. One approach could be to use public health indicators, for example suicide rates, as a measure of social mood. Also, statistical agencies are increasingly collecting nonmonetary macroeconomic indicators - for example, the UK's Office of National Statistics (ONS) now collects survey data on people's perceptions of their own wellbeing. Nonetheless, standard econometric modelling is likely to suffer from data constraints, so the other empirical route would be to use structural modelling and/or agent-based modelling to match the predictive power of these different models against real-world trends.

This type of approach can also be used to embed social and political influences, including the real-world political events that propel macroeconomic policies and outcomes. For example, in the context of recent debates about whether or not austerity will solve problems of macroeconomic instability, focusing on austerity reassures financial markets and may increase the supply of lending, enabling entrepreneurs to embark on new projects. On the other hand, it may dampen confidence, optimism and the animal spirits of entrepreneurs, leading to falling discount factors, increased shorttermism and faltering private fixed asset investment with negative impacts on aggregate demand in the short term and an erosion of future productive capacity in the long term.

The impact of political rhetoric does not necessarily have to have any link with realised economic decisions; it is its impact on the psychology of finance and entrepreneurship that is important. It is the rhetoric that affects the animal spirits and financial expectations that in turn drive the responses to political news and events. Negative political rhetoric undermines confidence and dampens animal spirits. It generates pessimism, shorttermism/present bias and risk aversion - all of which catalyse caution and delay. Either way, it is important to have a model that helps us to understand how political policies and rhetoric impact on decisions affecting the macroeconomy. Behavioural macroeconomic models can play this role.

5. This is a simple, restricted form of hyperbolic discount function. More complex forms embed additional parameters (see Frederick et al. 2002 and Baddeley 2013 for surveys of different approaches). The same basic insights will apply. 


\section{POLICY IMPLICATIONS}

Behavioural macroeconomics approaches generate relatively new sets of policy implications focusing on the insight that macroeconomic and financial policies should be designed to address a number of sources of socio-psychological instability in the macroeconomy and financial system. Policies should be designed to constrain the negative consequences of moods, emotions and present bias. For example, policies could focus on reviving animal spirits via more positive political rhetoric. The problem with austerity debates in the UK, for example, is that whilst the rhetoric focuses on austerity, the reality is that there is no automatic connection between the rhetoric and what is really happening with public deficits/debt. This potentially means that austerity rhetoric generates the worst of both worlds: a rhetoric focusing on austerity that's not necessarily happening can unnecessarily dampen animal spirits and entrepreneurs' hopes for the future, leading to selffulfilling prophecies of sluggishness and stagnation. Politicians need to consider more carefully the overall impact of pessimistic rhetoric on animal spirits and business confidence.

Another key aspect of policy could be for the public sector to lead from the front via public investment in projects delivering concrete returns in the long term; for example, infrastructure projects can boost animal spirits and/or generate output and employment in the short term alongside greater business confidence about the future. These projects should be assessed carefully to ensure that they also deliver substantive, long-term benefits in terms of boosting productivity and growth. Governments can encourage entrepreneurs' forward-looking behaviour via tax incentives and subsidies. In terms of availability of finance, government guarantees and other policies to encourage bank lending will alleviate the financing constraints that compound pessimism and present bias amongst entrepreneurs.

\section{CONCLUSIONS}

To conclude: can we decant animal spirits into behavioural macroeconomics? Is it defensible to build a micro-founded behavioural macro model on animal spirits? One methodological issue to consider is whether or not the macroeconomy can be understood in terms of micro-foundations. If an approach of methodological individualism can be adopted, a key question must be: how do we capture the interactions between agents effectively to resolve aggregation problems? On the other hand, if the macroeconomy cannot be analysed using microeconomic building blocks and methodological holism is the only defensible approach, then how do we conceptualise the macroeconomy and how do animal spirits drive the macroeconomy as a whole? These problems raise the additional question of whether or not animal spirits are really empirically tractable. Standard approaches have modelled them as exogenous noise, but is it possible to separate animal spirits noise from other sources of noise?

Overall, attempting to reconcile macroeconomics and behavioural economics can raise as many questions as it answers, particularly because behavioural economics is most powerful when it is applied to the analysis of microeconomic behaviours. The macroeconomy is a complex system, and any approach that does not properly address the behavioural and socio-psychological factors driving the individual actors that constitute the macroeconomy is unlikely to capture the instability effectively.

This paper has addressed the focus in behavioural macroeconomics on the role played by animal spirits. Animal spirits have not so far been convincingly embedded into 
macroeconomic theory, so more work is needed to define what animal spirits really are and how they connect with emotions and time preference. An assessment should also be made about whether or not animal spirits should be the ultimate psychological explanatory variable in a behavioural macroeconomics model. There are a series of empirical questions too. Animal spirits are by their nature unquantifiable, but if we cannot give them some sort of empirical validity then animal spirits models will be of little use to real-world policy-makers. Traditional econometric approaches are unlikely to be the best approach, because macroeconomic data on socio-psychological variables are not readily available. Instead, using agent-based models or other computational methods to embed psychological factors are potentially fruitful avenues for future empirical research.

\section{REFERENCES}

Akerlof, G., Shiller, R. (2009): Animal Spirits: How Human Psychology Drives the Economy and Why it Matters for Global Capitalism, Princeton, NJ: Princeton University Press.

Angeletos, G.-M., Laibson, D., Repetto, A., Tobacman, J., Weinberg, S. (2001): The hyperbolic consumption model: calibration, simulation, and empirical evaluation, in: Journal of Economic Perspectives, 15(3), 47-68.

Avery, C., Zemsky, P. (1998): Multi-dimensional uncertainty and herd behavior in financial markets, in: American Economic Review, 88, 724-748.

Baddeley, M. (2006): Behind the Black Box: a survey of real-world investment appraisal approaches, in: Empirica, 33(5), 329-350.

Baddeley, M. (2010): Herding, social influence and economic decision-making: socio-psychological and neuroscientific analyses, in: Philosophical Transactions of the Royal Society B, 365(1538), 281-290.

Baddeley, M.C. (2013): Behavioural Economics and Finance, Abingdon: Routledge.

Baddeley, M., Curtis, A., Wood, R. (2005): An introduction to prior information derived from probabilistic judgments; elicitation of knowledge, cognitive bias and herding, in: Curtis, A., Wood, R. (eds), Geological Prior Information: Informing Science and Engineering, Special Publications No. 239, London: Geological Society, 15-27.

Banerjee, A. (1992): A simple model of herd behavior, in: Quarterly Journal of Economics, 107(3), 797-817.

Bechara, A., Damasio, A.R. (2004): The somatic marker hypothesis - a neural theory of economic decision, in: Games and Economic Behavior, 52(2005), 336-372.

Bernheim, B.D., Rangel, A. (2004): Addiction and cue-triggered decision processes, in: American Economic Review, 94(5), 1558-1590.

Bikhchandani, S., Hirshleifer, D., Welch, I. (1992): A theory of fads, fashions, custom and cultural change as informational cascades, in: Journal of Political Economy, 100(5), 992-1026.

Bikhchandani, S., Hirshleifer, D., Welch, I. (1998): Learning from the behavior of others: conformity, fads, and informational cascades, in: Journal of Economic Perspectives, 12(3), 151-170.

Chamley (2004): Rational Herds: Economic Models of Social Learning, Cambridge, UK: Cambridge University Press.

Costandi, M. (2006): Exorcising animal spirits: the discovery of nerve function, in: Neurophilosophy, URL: http://neurophilosophy.wordpress.com/2006/11/16/exorcising-animal-spirits-the-discoveryof-nerve-function/.

Damasio, A.R. (2005): Descartes' Error: Emotion, Reason, and the Human Brain, London: Vintage.

Davidson, P. (1997): Are grains of sand in the wheels of international finance sufficient to do the job when boulders are often required?, in: The Economic Journal, 107(442), 671-686.

Davidson, P. (2008): Securitization, liquidity, and market failure, in: Challenge, 51(3), 43-56.

De Grauwe, P. (2011): Animal spirits and monetary policy, in: Economic Theory, 47, 423-457.

De Grauwe, P. (2012a): Lectures on Behavioural Macroeconomics, Princeton, NJ: Princeton University Press. 
De Grauwe, P. (2012b): Booms and busts in economic activity: a behavioural explanation, in: Journal of Economic Behavior and Organisation, 83(3), 484-501.

Dow, S.C. (2011): Cognition, sentiment and financial instability: psychology in a Minsky framework, in: Cambridge Journal of Economics, 35(2), 233-250.

Dow, A., Dow, S. (1985): Animal spirits and rationality, in: Lawson, T., Pesaran, H. (eds), Keynes' Economics - Methodological Issues, Beckenham, UK: Croom Helm, 46-55.

Dow, A., Dow, S. (2011): Animal spirits revisited, in: Capitalism \& Society, manuscript no. 1087.

Elster, J. (1996): Rationality and the emotions, in: Economic Journal, 106(438), 136-197.

Elster, J. (1998): Emotions and economic theory, in: Journal of Economic Literature, 36(1), 47-74.

Farmer, Roger E.A., Guo, J.-T. (1994): Real business cycles and the animal spirits hypothesis, in: Journal of Economic Theory, 63, 42-73.

Fisher, I. (1930): The Theory of Interest, New York: Macmillan.

Frederick, S., Lowenstein, G., O'Donoghue, T. (2002): Time discounting: a critical review, in: Journal of Economic Literature, 40(2), 351-401.

Gigerenzer, G. (2007): Gut Feelings: The Intelligence of the Unconscious, London: Penguin.

Gigerenzer, G., Goldstein, D.G. (1996): Reasoning the fast and frugal way: models of bounded rationality, in: Psychology Reviews, 103, 650-669.

Harlow, John Martyn (1868): Recovery from the passage of an iron bar through the head, in: Publications of the Massachusetts Medical Society, 2, 327-347.

Howitt, P., McAfee, R.P. (1992): Animal spirits, in: American Economic Review, 82(3), 493-507.

Katona, G. (1975): Psychological Economics, New York: Elsevier.

Keynes, J.M. (1930): A Treatise on Money, London: Macmillan.

Keynes, J.M. (1936): The General Theory of Interest, Employment and Money, London: Macmillan.

Keynes, J.M. (1937): The general theory of employment, in: Quarterly Journal of Economics, 51, 209-223.

Koppl, R. (1991): Retrospectives: animal spirits, in: Journal of Economic Perspectives, 5(3), 203-210.

Koppl, R. (2002): Big Players and the Economic Theory of Expectations, Basingstoke, UK: Palgrave Macmillan.

Koutsobinas, T. (2011): Animal spirits, liquidity-preference and Keynesian behavioural macroeconomics: an intertemporal framework, MPRA Working Paper 43027, Munich: University Library of Munich.

Laibson, D. (1997): Golden eggs and hyperbolic discounting, in: Quarterly Journal of Economics, 112, 443-478.

Loewenstein, G. (1996): Out of control: visceral influences on decision making, in: Organizational Behavior and Human Decision Processes, 65(3), 272-292. (Reprinted in Camerer et al. (2004), Advances in Behavioral Economics, Princeton, NJ: Princeton University Press / Russell Sage Foundation.)

Loewenstein, G.F., O’Donoghue, T. (2004): Animal spirits: affective and deliberative processes in economic behaviour, Center for Analytic Economics CAE Working Paper 04-14, New York: Cornell University.

Loewenstein, G.F., Weber, E.U., Hsee, C.K., Welch, N. (2007): Risk as feelings, in: Loewenstein, G.F. (ed.), Exotic Preferences: Behavioral Economics and Human Motivation, Oxford: Oxford University Press, 567-611.

Mankiw, N.G. (2012): Macroeconomics, Basingstoke, UK: Macmillan.

Martins, N. (2011): Can neuroscience inform economics? Rationality, emotions and preference formation, in: Cambridge Journal of Economics, 35(2), 251-267.

Mini, P. (1990): Keynes, Bloomsbury and The General Theory, London: Macmillan.

Minsky, Hyman P. (1978): The financial instability hypothesis: a restatement, Thames Papers in Political Economy, North East London Polytechnic.

Minksy, H.P. (1986): Stabilizing An Unstable Economy, New Haven, CT: Yale University Press.

Minsky, H.P. (1992): The financial instability hypothesis, Levy Institute Working Paper No. 74, May.

O’Donoghue, T., Rabin, M. (1999): Doing it now or later, in: American Economic Review, 89(1), 103-124.

Scharfstein, D.S., Stein, J.C. (1990): Herd behaviour and investment, in: American Economic Review, 80(3), 465-479. 
112 European Journal of Economics and Economic Policies: Intervention, Vol. 11 No. 1

Shiller, R. (2000): Irrational Exuberance, Princeton, NJ: Princeton University Press.

Shiller, R. (2003): From efficient markets theory to behavioral finance, in: Journal of Economic Perspectives, 17(1), 83-104.

Thaler, R., Shefrin, H.M. (1981): An economic theory of self control, in: Journal of Political Economy, 89(2), 392-406.

Tversky, A., Kahneman, D. (1974): Judgement under uncertainty: heuristics and biases, in: Science, $185,1124-1131$.

Woodford, M. (1988): Expectations, finance constraints, and aggregate instability, in: Kohn, M., Tsiang, S.C. (eds), Finance Constraints, Expectations, and Macroeconomics, New York: Oxford University Press, 230-261.

Woodford, M. (1990): Learning to believe in sunspots, in: Econometrica, 58, 277-307. 